\title{
Tear Film Functions and Dry Eye Symptoms in Young Patients with Pterygium
}

\author{
Erkut Kucuk, ${ }^{1}$ () Ugur Yilmaz, ${ }^{2}$ (1) Kursad Ramazan Zor ${ }^{1}$ \\ ${ }^{1}$ Department of Ophthalmology, Nigde Omer Halisdemir University Faculty of Medicine, Nigde, Turkey \\ ${ }^{2}$ Department of Ophthalmology, Pamukkale University Faculty of Medicine, Denizli, Turkey
}

\begin{abstract}
Objectives: This study was performed to evaluate the Schirmer II test (ST2) results, tear breakup time (TBUT) findings, and Ocular Surface Disease Index (OSDI) scores of pterygium patients under 30 years of age, and to compare the results with pterygium patients aged 30 years and older and healthy controls.

Methods: Eighty-four eyes of 60 patients who had primary pterygium and were younger than 30 years of age (Group I), 79 eyes of 53 patients who had primary pterygium and were 30 years of age and older (Group 2), and 64 eyes of 64 healthy controls (Group 3) were included in the study. The results of ST2 and TBUT tests and the OSDI questionnaire scores were recorded and compared.

Results: Group I had lower TBUT values compared to Group 2 and the control group $(p=0.03$ and $p<0.00$ I, respectively). Group I had lower ST2 values than the control group $(p<0.00 I)$. There was no significant difference in the ST2 results between Group I and Group $2(p=0.08)$. Group I had higher OSDI scores than the control group $(p=0.003)$. There was no significant difference in the OSDI scores between Group I and Group 2 ( $p=0.7)$.

Conclusion: The results indicated that young patients with pterygium had lower ST2 results, lower TBUT values, and higher OSDI scores compared to the control group, and lower TBUT values compared to older patients with pterygium. Tear film abnormality may be a factor in the pterygium pathogenesis, especially in young patients, and may increase the vulnerability of the ocular surface of young people to environmental factors, leading to pterygium formation.
\end{abstract}

Keywords: Dry eye, ocular surface disease index, pterygium, Schirmer test, tear breakup time.

\section{Introduction}

Pterygium is a common disease of the ocular surface. It is characterized by growth of conjunctival tissue on the cornea. Although the prevalence varies according to geographical location, it is reported to be around 10\% worldwide, and has been noted as slightly more prevalent in men ( $\mathrm{I}$, 2). Numerous studies have investigated the pathogenesis of pterygium, but the precise mechanism underlying the pterygium is still unknown (3-5). Several risk factors have been reported to be associated with pterygium formation. Among them, ultraviolet light (UV) exposure is regarded as a major factor (6-9). UV light is thought to cause oxidative stress, which leads to genetic damage and activation of inflammatory pathways and growth factors that are important in the pathogenesis of pterygium (5). Age is also considered a risk factor. Most studies have reported an increased prevalence of pterygium with increasing age and a very low prevalence in young patients $(\mathrm{I}, \mathrm{I}, \mathrm{I}, \mathrm{II})$. This is generally attributed to cumulative UV light exposure. Although less prevalent in young people, when present, pterygium in young patients

Address for correspondence: Erkut Kucuk, MD. Nigde Omer Halisdemir Universitesi Tip Fakultesi, Goz Hastaliklari Anabilim Dali, Nigde, Turkey

Phone: +90 5057484290 E-mail: erkutkucuk@yahoo.com

Submitted Date: October 13, 2019 Accepted Date: December 22, 2019 Available Online Date: February 14, 2020

${ }^{\circ}$ Copyright 2020 by Beyoglu Eye Training and Research Hospital - Available online at www.beyoglueye.com OPEN ACCESS This work is licensed under a Creative Commons Attribution-NonCommercial 4.0 International License. 
can pose some difficulties in management. The recurrence rate after surgery has been reported to be higher in young patients (12). Since not all patients living under the same environmental conditions develop pterygium, it is probable that several factors play a role in the pathogenesis of the condition. Several studies have evaluated the role of dry eye in pterygium patients. Most studies have reported no significant difference in Schirmer test (ST) results, but decreased tear breakup time (TBUT) results in pterygium patients compared to healthy controls and improvement in TBUT scores after pterygium excision have been reported (13-16). It is possible that factors other than UV light may affect the pathogenesis of pterygium in young patients, since there is less cumulative UV exposure. One of these factors may be impaired tear function. In this study, the authors investigated tear function test results and ocular surface disease index (OSDI) scores of pterygium patients under 30 years of age and compared the results with pterygium patients older than 30. The results were also compared with healthy controls.

\section{Methods}

This controlled, multicenter study was performed in the Ophthalmology Department of Niğde Ömer Halisdemir University Training and Research Hospital and the Ophthalmology Department of Pamukkale University Hospital. Three groups were formed. Eighty-four eyes of 60 consecutive patients who admitted to the ophthalmology clinics who had primary pterygium and were younger than 30 years of age were included in the first group. Seventy-nine eyes of 53 patients who had primary pterygium and were 30 years of age and older were included in the second group. Sixtyfour eyes of 64 individuals who did not have any ophthalmic disease other than refractive problems constituted the control group. Subjects who had corneal pathologies other than pterygium, allergic conditions, meibomian gland dysfunction, or active ocular infection were excluded from all groups. The use of contact lenses or drugs that can affect the lacrimal system were also among the exclusion criteria. The OSDI questionnaire is commonly used to evaluate symptoms of dry eye. All of the study participants completed the OSDI questionnaire. All of the participants also underwent an ophthalmological examination, including measurements of best corrected visual acuity, anterior and posterior segment examination using a slit-lamp, and intraocular pressure measurement. For TBUT measurements, a drop of $2 \%$ fluorescein solution was applied to the lateral inferior fornix. The patient was asked to blink several times for uniform distribution of the fluorescein and then instructed to look ahead without blinking. The time from the last blink to the appearance of the first dry spot on the cornea was recorded using the cobalt blue filter of the biomicroscope and a stopwatch.
Three consecutive measurements were made and the mean was recorded. Thirty minutes later, in a dimly lit examining room, a topical anesthetic agent, proparacaine hydrochloride $0.5 \%$ drops (Alcaine; Alcon Laboratories, Fort Worth, TX, USA), was applied to the inferior fornix, and 3 minutes later, a standard ST2 filter strip (Bio Schirmer; Biotech Vision Care, Ahmedabad, Gujarat, India) was inserted into the lateral inferior fornix at the junction of the middle and lateral thirds of the lower eyelid, taking care to not to touch the cornea. The patient was asked to keep their eyes open and blink as necessary. The filter strip was removed after 5 minutes, and wetting of the measurement strip was measured and recorded. This study was performed according to the tenets of Declaration of Helsinki and the study received approval from Non-Invasive Clinical Research Committee of Pamukkale University on 06/07/2017. Detailed information about the procedures to be performed was given to all of the participants, and written and verbal informed consent was provided.

\section{Statistical Analysis}

Statistical analysis was performed using IBM SPSS Statistics for Windows, Version 20.0 (IBM Corp., Armonk, NY, USA). Chi-square test was used to compare groups according to gender. One-way analysis of variance with the Tukey Honest Significant Difference test was used to compare groups for TBUT, ST2 values, and OSDI scores. In all of the analyses, a $P$ value $<0.05$ was considered statistically significant.

\section{Results}

There was no statistically significant difference in gender between groups $(p=0.27 I)$ (Table I). All of the pterygia were on the nasal conjunctiva. The mean age was $24.7 \pm 3.8$ years for the pterygium group younger than 30 years of age (Group I), $40.6 \pm 6.9$ for the pterygium group 30 years and older (Group 2), and 25.8 \pm 3.5 years for the control group. In Group I, there were 24 patients with bilateral pterygium and 36 patients with unilateral pterygium among a total of 60 patients and 84 eyes. In Group 2, there were 26 patients with bilateral pterygium and 27 patients with unilateral pterygium among a total of 53 patients and 79 eyes. A total of 64 eyes of 64 individuals were included in the control group of the study.

The summary of the test results and statistical analysis is provided in Table 2. The mean values of the TBUT test in Group I, Group 2, and the control group eyes were $8.2 \pm 4.2$ seconds, $9.7 \pm 5.1$ seconds, and $13.4 \pm 5$.I seconds, respectively. Group I had lower TBUT values compared to Group 2 and the control group ( $p=0.03$ and $p<0.001$, respectively). The mean values of the ST2 test in Group I, Group 2, and the control group eyes were $13.5 \pm 8.0 \mathrm{~mm}, 11.4 \pm 7.9 \mathrm{~mm}$, and $17.4 \pm 7.8 \mathrm{~mm}$, respectively. Group I had a lower ST2 value than the control 
Table I. Demographic characteristics of the groups

\section{Pterygium group $<30$ years $n=60$}

(Group I)
Pterygium group $\geq 30$ years
$\mathbf{n}=\mathbf{5 3}$

(Group 2)
Control group $n=64$

(Group 3)

\begin{tabular}{|c|c|c|c|}
\hline \multicolumn{4}{|l|}{ Age (years) } \\
\hline Mean $\pm S D$ & $24.7 \pm 3.8$ & $40.6 \pm 6.9$ & $25.8 \pm 3.5$ \\
\hline Range & $18-29$ & $30-62$ & $18-29$ \\
\hline \multicolumn{4}{|l|}{ Gender } \\
\hline Female, n (\%) & $27(45)$ & $27(50.9)$ & $34(53)$ \\
\hline Male, n (\%) & $33(55)$ & $26(49.1)$ & $30(47)$ \\
\hline
\end{tabular}

Table 2. Tear breakup time, Schirmer II test, and Ocular Surface Disease Index results of the groups

\section{Pterygium group $<30$ years \\ $n=60$ \\ 84 eyes}

(Group I)

\section{Pterygium group $\geq 30$ years $n=53$ 79 eyes}

\section{Control \\ $\mathrm{n}=64$ \\ 64 eyes}

p

\begin{tabular}{|c|c|c|c|c|}
\hline \multicolumn{5}{|l|}{ TBUT (s) } \\
\hline Mean \pm SD & $8.2 \pm 4.2^{\mathrm{a}}$ & $9.7 \pm 5.1^{b}$ & $13.4 \pm 5.1^{c}$ & \multirow[t]{2}{*}{$<0.05$} \\
\hline Range & $2-20$ & $2-24$ & $3-25$ & \\
\hline \multicolumn{5}{|l|}{ ST2 (mm) } \\
\hline Mean \pm SD & $13.5 \pm 8.0^{\mathrm{a}}$ & $11.4 \pm 7.9^{a}$ & $17,4 \pm 7.8^{b}$ & \multirow[t]{2}{*}{$<0.05$} \\
\hline Range & $3-28$ & $2-30$ & $3-29$ & \\
\hline \multicolumn{5}{|l|}{ OSDI score } \\
\hline Mean $\pm S D$ & $24.5 \pm 8.5^{\mathrm{a}}$ & $23.0 \pm 11.8^{\mathrm{a}}$ & $17.2 \pm 7.5^{b}$ & \\
\hline Range & $9-50$ & $6-55$ & $5-32$ & $<0.05$ \\
\hline
\end{tabular}

Means in a row that have no superscript in common are significantly different from each other; $\mathrm{P}$ values are obtained from one-way analysis of variance; OSDI: Ocular Surface Disease Index; ST2: Schirmer II test;TBUT:Tear breakup time.

group $(p<0.00 \mathrm{I})$. There was no significant difference in the ST2 results between Group I and Group $2(p=0.08)$. The mean values of the OSDI score for Group I, Group 2, and the control group were 24.5 points, 23.0 points, and 17.2 points, respectively. Group I had a higher OSDI score than the control group $(p=0.003)$. There was no significant difference in the OSDI score between Group I and Group 2 ( $p=0.7)$.

\section{Discussion}

Chronic UV light exposure is accepted as an important factor in the pathogenesis of pterygium $(6-9,17,18)$. UV light-mediated oxidative stress and limbal damage play an important role in pterygium pathogenesis $(4,5)$. However, many people living in the same environmental conditions with the same UV light exposure do not develop pterygium (13). Also, although both eyes of an individual are exposed to same amount of ultraviolet radiation (UVR), pterygium is frequently unilateral (14). The proposed UVR focus at the nasal limbus does not completely explain the formation of temporal corneal pterygium (19). Other factors are also likely involved in the pterygium pathogenesis. The effect of UVR exposure is believed to be cumulative due to chronic exposure. The prevalence of pterygium has been reported to be lower in young people and to increase with age (I, I0, II, 20). Recently, in a meta-analysis, Rezvan et al. (2I) evaluated 68 studies with a total of 4I5,9II participants and investigated the global prevalence and risk factors for pterygium. Similarly, they found that the prevalence of pterygium increased with age. Another meta-analysis from China also found that age was a significant risk factor for pterygium (22). They linked this finding to the effects of UVR exposure and increasing vulnerability in older people in their study. However, it is also notable that the recurrence rate after pterygium surgery is reported to be higher in young ptery- 
gium patients (12). Based on these data, we wanted to evaluate young patients with pterygium, since they have a lower cumulative exposure to UVR, and examining other factors may be more important in these patients. In this study, we evaluated one of the other proposed factors, the presence of dry eye, in young pterygium patients. There are several studies evaluating tear function tests in pterygium patients; however, the mean age was typically above 40 years in these studies $(13,14,23,24)$. We formed 2 groups based on the age of patients: below 30 years of age and 30 years and older in this study. The mean age was 24.7 years in the first group and 40.6 years in the second group. We performed TBUT test and ST2. We preferred ST with anesthesia (ST2) because it has been reported to be more reliable in diagnosing dry eye (25). We also compared the results of these groups with healthy controls. Lower TBUT values were observed in young pterygium patients compared to the older patients. There was no significant difference in the ST2 results compared to the older group. The TBUT and ST2 results were also lower than the control group. Kadayifcilar et al. (13) reported that pterygium patients had lower TBUT results compared to a healthy control group, while ST result was not significantly different between groups. The mean age of the participants in that study was 46.06 years. Ozsutcu et al. (23) investigated the TBUT and ST results of patients with unilateral pterygium who had a mean age of $4 \mathrm{I}$ years. They compared the results of eyes with pterygium to the fellow eyes. They found that both TBUT and ST values were significantly lower in the eyes with pterygium. Ishioka et al. (14) also compared the results of eyes with pterygium and the fellow eye in patients with unilateral pterygium. They also found lower TBUT and ST2 values in the eyes with pterygium. In their study, the results of an ST without anesthesia was not significantly different between groups. It has been reported in several studies that TBUT results improved after pterygium surgery $(15,26)$. Tan et al. $(27)$ reported that recurrent pterygium was associated with dry eye. They found lower ST values in patients with recurrent pterygium. Ye et al. (16) also reported lower TBUT values in pterygium patients compared with healthy controls. Shah et al. (28) also reported that dry eye was a risk factor for pterygium formation, but they did not report the results of TBUT or ST results in their study. The results of this previous research indicate that the quantity, quality, and composition of the tear film may be affected in pterygium patients. We found similar results in the present study: lower ST2 and TBUT results compared to a healthy, age-matched control group. One of our findings, a lower TBUT value in young pterygium patients compared to older patients with pterygium, has not been previously reported in the literature, to the best of our knowledge.
Although few, there are other studies that did not any report difference in tear function tests in pterygium patients $(29,30)$. Compensatory mechanisms, like increased blinking and reflex stimulation of lacrimal and meibomian glands, may result in transient improvements in tear film stability, especially in mild forms of dry eye disease (3I). We think that these mechanisms may have been responsible for normal tear function test measurements reported in other studies.

ST values and tear film stability were reported to decrease with age (32-35). The prevalence of dry eye disease also increases with age (36). It would be expected that a pterygium group younger than 30 years of age would have higher ST and TBUT results compared to an older group of patients. In contrast, in the present study, we found that young people with pterygium not only had lower ST2 and TBUT values compared to the healthy, age-matched controls, but also lower TBUT values compared with older patients with pterygium. The preocular tear film is the first defense of the ocular surface against environmental factors, including UV light (26). Abnormalities of the tear film may leave the ocular surface vulnerable to environmental factors. Both pterygium patient groups had lower TBUT and ST values compared to the control group in this study. This finding supports the results of previous studies reporting impaired tear function in pterygium patients. Although the ST results were similar between patient groups, the decreased TBUT and tear film stability in the younger age group may be a cause of early pterygium formation. Impaired tear film stability as evidenced by decreased TBUT values has been reported in pterygium studies $(13,15,16)$. Although young patients have a lower cumulative exposure to UV light than older patients with pterygium, decreased tear film stability may decrease the protection against UV light in these patients. These results suggest that tear function abnormalities may have a role in the pathogenesis of pterygium and tear film instability may cause early pterygium formation in young people.

ST and TBUT tests are frequently used to evaluate tear film and dry eye. Li et al. (25) reported that ST with topical anesthesia was more objective and reliable than the ST without anesthesia, and had a higher diagnostic value in patients with aqueous deficient dry eye. They found that anesthesia of the ocular surface thereby avoiding influencing factors led to an increased diagnostic value. Therefore, the ST2 was selected for the current study.

The OSDI is a reliable questionnaire used in the evaluation of dry eye symptoms and severity (37). Although it is not frequently used in the evaluation of patients with pterygium, in the present study, we used this questionnaire to evaluate dry eye symptoms in the study groups since we were evaluating tear function. Ye et al. (16) found significantly higher OSDI scores in patients with pterygium com- 
pared with healthy controls. Several studies investigating the prevalence of dry eye have reported an association between dry eye and pterygium. Hashemi et al. (38) found that an abnormal ST result was associated with pterygium and the odds of pterygium in cases with an OSDI of 23 or more was I.7 times higher. They concluded that pterygium was associated with dry eye and increased the symptoms of dry eye. Using another dry eye questionnaire, Lee et al. (39) reported a twofold greater risk of dry eye symptoms in patients with pterygium and regarded pterygium as an independent risk factor for dry eye. Both pterygium groups had higher OSDI scores compared to the control group in our study. These results indicate that, in addition to impaired tear function, pterygium patients also have worse dry eye symptoms.

\section{Conclusion}

In conclusion, to our knowledge, this is the first study evaluating tear function in young patients with pterygium. The results of this study indicated that young patients with pterygium had lower ST and TBUT values, and higher OSDI scores compared to healthy controls. In addition, young patients with pterygium had lower TBUT values compared to older pterygium patients. Tear film abnormality and dry eye may be a factor in the pterygium pathogenesis, especially in young patients, and may increase the vulnerability of the ocular surface of the young people to environmental factors, leading to pterygium formation.

\section{Disclosures}

Ethics Committee Approval: The Ethics Committee of Pamukkale University provided the ethics committee approval for this study (60116787-020/43817 - 6/7/2017).

Peer-review: Externally peer-reviewed.

Conflict of Interest: None declared.

Authorship Contributions: Involved in design and conduct of the study (EK, UY, KRZ); preparation and review of the study (EK, UY, KRZ); data collection (EK, KRZ); and statistical analysis (EK, UY).

\section{References}

I. Liu L, Wu J, Geng J, Yuan Z, Huang D. Geographical prevalence and risk factors for pterygium: a systematic review and metaanalysis. BM] Open 2013;3:e003787. [CrossRef]

2. Droutsas K, Sekundo W. Epidemiology of pterygium. A review. [Article in German] Ophthalmologe 2010;107:5 I I-2. [CrossRef]

3. Liu T, Liu Y, Xie L, He X, Bai J. Progress in the pathogenesis of pterygium. Curr Eye Res 2013;38:1 191-7. [CrossRef]

4. Bradley JC, Yang W, Bradley RH, Reid TW, Schwab IR. The science of pterygia. Br J Ophthalmol 2010;94:8I5-20. [CrossRef]

5. Di Girolamo N, Chui J, Coroneo MT, Wakefield D. Pathogenesis of pterygia: role of cytokines, growth factors, and matrix metalloproteinases. Prog Retin Eye Res 2004;23:195-228. [CrossRef]
6. Taylor HR, West SK, Rosenthal FS, Munoz B, Newland HS, Emmett EA. Corneal Changes Associated With Chronic UV Irradiation. Arch Ophthalmol 1989;107:148I-4. [CrossRef]

7. Oliva MS, Taylor H. Ultraviolet radiation and the eye. Int Ophthalmol Clin 2005;45:1-17.

8. Sherwin JC, Hewitt AW, Kearns LS, Griffiths LR, Mackey DA, Coroneo MT. The association between pterygium and conjunctival ultraviolet autofluorescence: the Norfolk Island Eye Study. Acta Ophthalmol 2013;91:363-70. [CrossRef]

9. McKnight CM, Sherwin JC, Yazar S, Forward H, Tan AX, Hewitt AW, et al. Pterygium and conjunctival ultraviolet autofluorescence in young Australian adults: the Raine study. Clin Exp Ophthalmol 2015;43:300-7. [CrossRef]

10. Fotouhi A, Hashemi H, Khabazkhoob M, Mohammad K. Prevalence and risk factors of pterygium and pinguecula: the Tehran Eye Study. Eye (Lond) 2009;23:I I 25-9. [CrossRef]

II. Jiao W, Zhou C, Wang T, Yang S, Bi H, Liu L, et al. Prevalence and risk factors for pterygium in rural older adults in Shandong Province of China: a cross-sectional study. Biomed Res Int 20| 4; 20 I 4:658648. [CrossRef]

12. Fernandes M, Sangwan VS, Bansal AK, Gangopadhyay N, Sridhar MS, Garg P, et al. Outcome of pterygium surgery: analysis over I 4 years. Eye (Lond) 2005; 19: I 182-90. [CrossRef]

13. Kadayifçilar SC, Orhan M, Irkeç M. Tear functions in patients with pterygium. Acta Ophthalmol Scand 1998;76: 176-9. [CrossRef]

14. Ishioka M, Shimmura S, Yagi Y, Tsubota K. Ptyerygium and Dry Eye Ophthalmologica 200I;215:209-II.[CrossRef]

15. Wang S, Jiang B, Gu Y. Changes of tear film function after pterygium operation. Ophthalmic Res 201 I;45:2 10-5. [CrossRef]

16. Ye F, Zhou F, Xia Y, Zhu X, Wu Y, Huang Z. Evaluation of meibomian gland and tear film changes in patients with pterygium. Indian J Ophthalmol 2017;65:233-7. [CrossRef]

17. Detorakis ET, Spandidos DA. Pathogenetic mechanisms and treatment options for ophthalmic pterygium: trends and perspectives (Review). Int J Mol Med 2009;23:439-47. [CrossRef]

18. Coroneo MT. Pterygium as an early indicator of ultraviolet insolation: a hypothesis. Br J Ophthalmol 1993;77:734-9. [CrossRef]

19. Islam SI, Wagoner MD. Pterygium in Young Members of One Family. Cornea 200I;20:708-10. [CrossRef]

20. Gazzard G, Saw SM, Farook M, Koh D, Widjaja D, Chia SE, et al. Pterygium in Indonesia: prevalence, severity and risk factors. $\mathrm{Br}$ J Ophthalmol 2002;86: 134I-6. [CrossRef]

21. Rezvan F, Khabazkhoob M, Hooshmand E, Yekta A, Saatchi M, Hashemi $\mathrm{H}$. Prevalence and risk factors of pterygium: a systematic review and meta-analysis. Surv Ophthalmol 2018;63:7I9-35.

22. Song P, Chang X, Wang M, An L. Variations of pterygium prevalence by age, gender and geographic characteristics in China: A systematic review and meta-analysis. PLoS One 2017; 12:e0 174587. [CrossRef]

23. Ozsutcu M, Arslan B, Erdur SK, Gulkilik G, Kocabora SM, Muftuoglu $\mathrm{O}$. Tear osmolarity and tear film parameters in patients 
with unilateral pterygium. Cornea 20।4;33:I I 74-8. [CrossRef]

24. Julio G, Lluch S, Pujol P, Alonso S, Merindano D. Tear osmolarity and ocular changes in pterygium. Cornea 2012;3I:|4I7-2I.

25. Li N, Deng XG, He MF. Comparison of the Schirmer I test with and without topical anesthesia for diagnosing dry eye. Int J Ophthalmol 2012;5:478-8I.

26. Li M, Zhang M, Lin Y, Xiao Q, Zhu X, Song S, et al. Tear function and goblet cell density after pterygium excision. Eye (Lond) 2007;21:224-8. [CrossRef]

27. Tan J, Vollmer-Conna U, Tat L. Coroneo M. Dry-Eye Disease in Recurrent Pterygium. Ophthalmic Res 2019;61:199-203. [CrossRef]

28. Shah SI, Shah SA, Rai P. Factors associated with pterygium based on history and clinical examination of patients in Pakistan. J Curr Ophthalmol 2016;28:91-2. [CrossRef]

29. Ergin A, Bozdoğan O. Study on tear function abnormality in pterygium. Ophthalmologica 200 I;215:204-8. [CrossRef]

30. Taylor HR. Studies on the tear film in climatic droplet keratopathy and pterygium. Arch Ophthalmol 1980;98:86-8. [CrossRef]

3I. Lemp MA, Bron AJ, Baudouin C, Benítez Del Castillo JM, Geffen $D$, Tauber J, et al. Tear osmolarity in the diagnosis and management of dry eye disease. Am J Ophthalmol 20I I;15I:792-8.el.

32. Mathers WD, Lane JA, Zimmerman MB. Tear film changes associated with normal aging. Cornea 1996;15:229-34. [CrossRef]
33. Patel S, Boyd KE, Burns J. Age, stability of the precorneal tear film and the refractive index of tears. Cont Lens Anterior Eye 2000;23:44-7.[CrossRef]

34. Maïssa C, Guillon M. Tear film dynamics and lipid layer characteristics--effect of age and gender. Cont Lens Anterior Eye 2010;33:176-82. [CrossRef]

35. Sweeney DF, Millar TJ, Raju SR. Tear film stability: a review. Exp Eye Res 2013; I 17:28-38. [CrossRef]

36. Farrand KF, Fridman M, Stillman IÖ, Schaumberg DA. Prevalence of Diagnosed Dry Eye Disease in the United States Among Adults Aged 18 Years and Older. Am J Ophthalmol 2017;182:90-8. [CrossRef]

37. Schiffman RM, Christianson MD, Jacobsen G, Hirsch JD, Reis BL. Reliability and validity of the Ocular Surface Disease Index. Arch Ophthalmol 2000; I 18:6 I5-2I. [CrossRef]

38. Hashemi $\mathrm{H}$, Khabazkhoob M, Kheirkhah A, Emamian $\mathrm{MH}$, Mehravaran S, Shariati M, et al. Prevalence of dry eye syndrome in an adult population. Clin Exp Ophthalmol 20।4;42:242-8.

39. Lee AJ, Lee J, Saw SM, Gazzard G, Koh D, Widjaja D, et al. Prevalence and risk factors associated with dry eye symptoms: a population based study in Indonesia. $\mathrm{Br} J$ Ophthalmol 2002;86: |347-51. [CrossRef] 